(C) [2008] IEEE. Reprinted, with permission, from [Youguang Guo, Xuefan Wang and Jianguo Zhu, Haiyan Lu, 2008 IEEE Industry Applications Society Annual Meeting, 2008]. This material is posted here with permission of the IEEE. Such ermission of the IEEE does not in any way imply IEEE endorsement of any of the University of Technology, Sydney's products or services. Internal or personal use of this material is permitted. However, permission to reprint/republish this material for advertising or promotional purposes or for creating new collective works for resale or redistribution must be obtained from the IEEE by writing to pubs-permissions@ieee.org. By choosing to view this document, you agree to all provisions of the copyright laws protecting it 


\section{Development of a Wound Rotor Brushless Doubly Fed Machine Based on Slot MMF Harmonics}

\author{
Youguang Guo \\ Faculty of Engineering and \\ Information Technology \\ University of Technology, Sydney \\ Sydney, Australia \\ youguang@eng.uts.edu.au
}

\author{
Xuefan Wang \\ College of Electrical and Electronic \\ Engineering \\ Huazhong University of Science and \\ Technology \\ Wuhan, China \\ xuefanwang@163.com
}

\author{
Jianguo Zhu, Haiyan Lu \\ Faculty of Engineering and \\ Information Technology \\ University of Technology, Sydney \\ Sydney, Australia \\ joe@eng.uts.edu.au, \\ helenlu@it.uts.edu.au
}

\begin{abstract}
In the rotor winding magnetomotive force (MMF) of an ac machine, there exist so-called slot harmonics which appear in pairs and the lower order harmonic of each pair rotates in the opposite direction against the fundamental component. In addition, the slot harmonics have the same winding factor as the fundamental component. Based on these properties, this paper develops a brushless doubly fed machine (BDFM) with wound rotor. The machine consists of two stator windings with $p_{1}$ and $p_{2}$ pole-pairs, respectively. The rotor has a normal symmetrical multi-phase winding, in which rotating MMFs with $p_{1}$ and $p_{2}$ pole-pairs are induced by their stator counterparts. When the number of rotor slots equals the sum of $p_{1}$ and $p_{2}$, the two MMFs rotate in opposite directions with respect to the rotor, satisfying the requirement of a BDFM. The major advantage of such a machine is that for both $p_{1}$ and $p_{2}$ pole-pair MMFs the winding factor is as high as that of the fundamental component, leading to high utilization of rotor winding and electrical efficiency.
\end{abstract}

Keywords-brushless doubly fed machine; slot harmonic magnetomotive force (MMF); wound rotor.

\section{INTRODUCTION}

Brushless doubly fed machines (BDFMs) possess many advantages and hence have attracted strong interest of research and application, especially for adjustable speed drives and variable speed generators [1-4]. The BDFM has two stator windings: a power winding with $p_{1}$ pole-pairs is connected directly to the grid, and a control winding with $p_{2}$ pole-pairs is connected via a power electronic converter, as illustrated in Fig. 1. While the grid supplies the major power to the power winding, the converter only needs to supply the so-called slip power to the control winding and hence its rating can be much lower than the machine. The greatly reduced rating and cost of the converter is a significant advantage compared to the conventional variable frequency variable speed drive, where the power electronic unit must have the same rating as the machine and correspondingly it is expensive. The other advantages of a BFDM include the controllable operation in synchronous mode over a wide range, adjustable power factor, lowered total harmonic distortion, and operation as a mains fed induction machine if the converter fails [5].

The balanced multi-phase currents in the power winding and those in the control winding generate a rotating magnetomotive force (MMF) with $p_{1}$ pole-pairs and a rotating MMF with $p_{2}$ pole-pairs respectively in the air gap. The two MMFs are designed to rotate in opposite directions with reference to the rotor, so that they combine to produce a single rotor frequency as

$$
f_{r}=\frac{p_{1}\left(n_{1}-n_{m}\right)}{60}=\frac{p_{2}\left(n_{m} \mp n_{2}\right)}{60}
$$

where $n_{1}=60 f_{1} / p_{1}$ and $n_{2}=60 f_{2} / p_{2}$ are the synchronous speeds of the air gap MMFs produced by the power winding current with $f_{1}$ frequency (mains frequency) and the control winding current with $f_{2}$ frequency, respectively, and $n_{m}$ is the rotor speed. The plus/minus sign corresponds to the positive/negative sequence of the control winding with respect to that of the power winding.

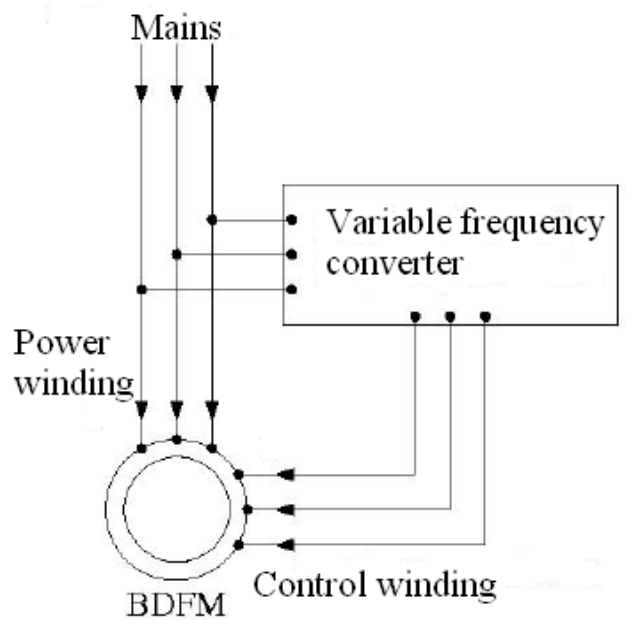

Figure 1. Configuration of a brushless doubly fed machine

The machine works in the synchronous operating mode with a constant speed, which is independent of the load. From (1), the rotor speed in rpm can be determined as

$$
n_{m}=60 \frac{f_{1} \pm f_{2}}{p_{1}+p_{2}}
$$


As the control winding is connected to the grid via the electronic converter, the rotor speed can be adjusted by varying the converter frequency, $f_{2}$, according to (2).

The rotor structure is a key factor affecting the performance of a BDFM, in which the rotor winding needs to be specially designed to couple the MMFs generated by both the stator power winding and control winding. Many BDFM designs have adopted the "nested loop" cage rotor, which was initially proposed by Broadway and Burbridge [6]. The simple nested loop type cage rotor is designed to produce contra rotating fields on the rotor, which were previously realized by the double-layer wound rotor. As described in [7], when a squirrel cage rotor with $Z$ bars is subjected to a rotating magnetic field of $p_{1}$ pole pairs, the induced rotor MMF contains main slot spatial harmonics of $p_{1} \pm Z$ pole pairs. When $p_{1} \pm Z$ is negative, the harmonic field rotates in the opposite direction against the main field of $p_{1}$ pole pairs relative to the rotor. This is a basic requirement for the second field of $p_{2}$ pole pairs for the synchronous operation of a BDFM.

Therefore, the rotor has $p_{1}+p_{2}$ bars (slots). When the number of rotor bars is small, short circuited loops need to be inserted between main bars for reducing the rotor slot field leakage in practical designs. As an example, when $Z=p_{1}+p_{2}=3+1=4$, the rotor has 4 nests and each nest has 5 concentric loops as illustrated in Fig. 2. The loops in one nest can be isolated or short circuited in one end by a common endring.

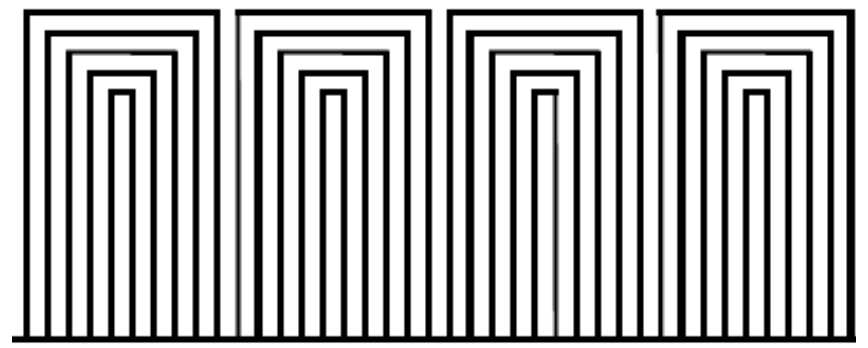

Figure 2. Nested loop design of a BDFM cage rotor

It is noted that $p_{1}$ and $p_{2}$ should be close. With a wide difference between the numbers of pole pairs, the chording factor of the short circuited loops would be small with respect to at least one of the numbers of pole pairs.

A large amount of work has been conducted on the cage rotor structure for improving the performance of BDFMs, but only limited success has been achieved so far because some of their intrinsic drawbacks have not been overcome, e.g. the rotor winding must be concentric short-circuited loops. On the other hand, the reluctance rotor has to be salient. These constraints have made the performance of BDFMs much lower than conventional AC machines, such as low utilization of rotor winding, and hence the BDFMs have not been successfully commercialized.

Despite the relatively complex winding manufacturing, the wound rotor offers flexible configuration and flexible connection. With the help of the theory on changing the number of poles, one can control and choose the major winding parameters for the optimum performance of the BDFM, such as $p_{1}, p_{2}$, number of rotor slots, rotational direction of MMF, winding distribution factor, and contents of harmonics. Based on these techniques, particularly the slot MMF harmonics produced by the rotor currents, this paper presents the development of a wound rotor BDFM with high performance such as high winding utilization.

\section{PRINCIPLE OF WOUND ROTOR BDFM BASED ON SLOT MMF HARMONICS}

The stator and rotor windings of an ac machine are commonly placed in the stator and rotor slots along the air gap, respectively. Unless the winding is sinusoidally distributed, the currents in the multi-phase windings generate an MMF with a series of harmonics besides the fundamental component. The terms with $v=Z / p \pm 1$ orders are called the slot harmonics, where $Z$ is the number of rotor slots and $p$ is number of pole-pairs of the windings. In other words, the slot harmonics have polepairs of $Z \pm p$.

\section{A. Features of Slot MMF Harmonics}

For the $v$-th harmonic of an integer-slot winding, the winding factor can be calculated by

$$
\begin{aligned}
& k_{d y v}=k_{d v} k_{y v} \\
& k_{d v}=\frac{\sin v \frac{q \alpha}{2}}{q \sin \frac{v \alpha}{2}} \\
& k_{y v}=\sin v \frac{y \pi}{2 \tau}
\end{aligned}
$$

where $k_{d y v}, k_{d v}$ and $k_{y v}$ are the winding factor, distribution factor and chording factor, respectively, $q=Z /(2 m p)$ is the number of slots per pole per phase, $m$ is the number of phases, $\alpha=2 p \pi / Z$ is the slot pitch in electrical radians, $y$ is the chording pitch of coil in number of slots, and $\tau=Z /(2 p)$ is the pole pitch.

For the slot MMF harmonics, $v=Z / p \pm 1=2 m q \pm 1$, then (4) and (5) can be expressed as

$$
\begin{aligned}
& k_{d v}=\frac{\sin (2 m q \pm 1) \frac{q \alpha}{2}}{q \sin \frac{(2 m q \pm 1) \alpha}{2}}=\frac{\sin \left(q \pi \pm \frac{q \alpha}{2}\right)}{q \sin \left(\pi \pm \frac{\alpha}{2}\right)}= \pm k_{d 1} \\
& k_{y v}=\sin (2 m q \pm 1) \frac{y \pi}{2 \tau}=\sin \left(y \pi \pm \frac{y \pi}{2 \tau}\right)= \pm k_{y 1}
\end{aligned}
$$

Therefore, $k_{d y v}=k_{d y 1}$, i.e. the winding factor of the slot MMF harmonics equals that of the fundamental component. Similarly, one can show that all the harmonics with $v=2 m k q \pm 1(k=1,2$, 3...) have the same winding factor as the fundament component. However, the higher the harmonic order is, the less effect the harmonic has on the machine performance. 
For the $v$-th MMF harmonic,

$$
\begin{aligned}
& f_{A v}=F_{\phi v} \cos v \theta \cos \omega t \\
& f_{B v}=F_{\phi v} \cos v\left(\theta-\frac{2}{3} \pi\right) \cos \left(\omega t-\frac{2}{3} \pi\right) \\
& f_{C v}=F_{\phi v} \cos v\left(\theta-\frac{4}{3} \pi\right) \cos \left(\omega t-\frac{4}{3} \pi\right)
\end{aligned}
$$

where $f_{A v}, f_{B v}$ and $f_{c v}$ are the pulsating MMFs produced by three phase currents respectively. When $v=1$, the combination of three phase MMFs is

$$
f_{1}(t, \theta)=\frac{3}{2} F_{\phi 1} \cos (\omega t-\theta)
$$

It is a well-known conclusion that when the symmetrically distributed three phase windings are excited by balanced three phase currents, the superposition of three pulsating phaseMMFs results in a rotating MMF with constant speed and constant magnitude.

The slot MMF harmonics appear in pairs, e.g. $v=2 m q \pm 1$. For the lower order harmonic, $v=2 m q-1$, we have

$$
f_{v}(t, \theta)=\frac{3}{2} F_{\phi \nu} \cos (\omega t+(2 m q-1) \theta)
$$

Comparing (9) and (10), we can conclude that the slot harmonic MMF with order of $v=2 m q-1$ rotates in the opposite direction against the fundamental component. Similarly, one can show that the slot MMF harmonic with order of $v=2 m q+1$ and the fundamental component rotate in the same direction.

\section{B. BDFM Based on the Slot MMF Harmonics}

From the above analysis, it can be seen that the slot MMF harmonics have two noticeable features: (1) The winding factor equals that of the fundamental component; (2) The lower order of each pair rotates in the opposite direction against the fundamental component. These features can be employed for developing new rotor structure BDFMs.

According to the operation principle of a BDFM, the rotor winding should be able to produce two MMFs with different pole-pairs $\left(p_{1}\right.$ and $\left.p_{2}\right)$ and the two MMFs rotate in different directions. Therefore, the design procedure of windings can be: (1) Select the pole-pair $\left(p_{1}\right)$ of the power winding according to the desired base speed; (2) Select the pole-pair $\left(p_{2}\right)$ of the control winding considering the speed range; and (3) Select the number of rotor slots $(Z)$ satisfying the requirement for symmetrical rotor winding and $Z=p_{1}+p_{2}$.

It can be seen that the rotating MMF with $p_{2}$ pole-pair is always a slot harmonic when the fundament component is of $p_{1}$ pole-pair, or the rotating MMF with $p_{1}$ pole-pair is always a slot harmonic when the fundament component is of $p_{2}$ polepair. As the winding factor of the slot harmonic is the same as that of the fundament, one can design the rotor winding by considering the stator power winding only. That is, if the winding is designed to have a high winding factor with respect to $p_{1}$ pole-pair MMF component, the $p_{2}$ pole-pair component will certainly have a high winding factor. For example, when the rotor winding is a regular 3-phase $60^{\circ}$ phase-belt winding with respect to $p_{1}$, naturally it is so with respect to $p_{2}$. Therefore, such a rotor winding has high utilization for both stator power winding and stator control winding fields.

Furthermore, the design according to slot harmonic MMFs meets the general requirement of BDFM, e.g. that $p_{1}$ and $p_{2}$ are not equal for avoiding direct transformer coupling between the power winding and the control winding, and that the difference between $p_{1}$ and $p_{2}$ must be larger than 1 for avoiding unbalanced magnetic pull on the rotor. The slot harmonic MMFs of the same pair feature a difference of 2 between the numbers of pole-pairs.

\section{DESIGN EXAMPLE}

A slot harmonic BDFM has been designed and analyzed. The power winding has 7 pole-pairs and the rotor employs regular 3-phase $60^{\circ}$ phase-belt symmetrical winding. The number of pole-pairs of the control winding is chosen as 5, so the number of rotor slots is 12 .

To achieve a 3 -phase regular $60^{\circ}$ phase-belt winding for $Z=12$ and $p_{1}=7$, the slot-number phase diagram is plotted as shown in Fig. 3(a), from which the slot numbers for each phase are determined as shown in Fig. 3(b). It can be seen that the slots (winding conductors) of each phase is within $60^{\circ}$ phasebelt and the distribution factor can be computed as 0.9659 .

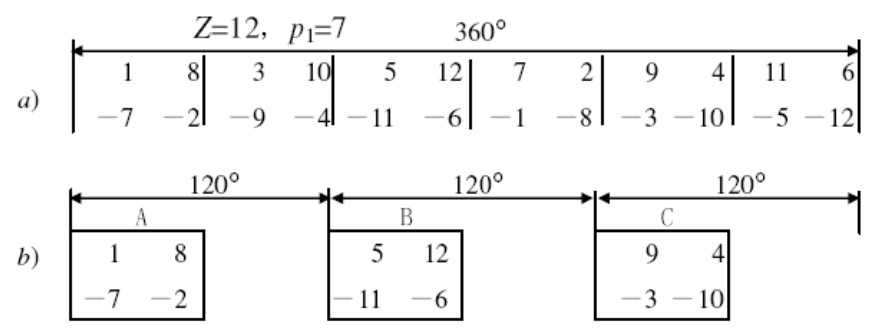

Figure 3. (a) Slot-number phase diagram $\left(Z=12, p_{1}=7\right)$, (b) determination of slot numbers for 3 phases

Fig. 4(a) shows the slot-number phase diagram for $Z=12$ and $p_{2}=5$, in which the slot numbers of each phase, determined by Fig. 3(b), are re-plotted. It can be seen that the slots of each phase is also within $60^{\circ}$ phase-belt and the distribution factor is 0.9659. This agrees with the property of slot harmonics.

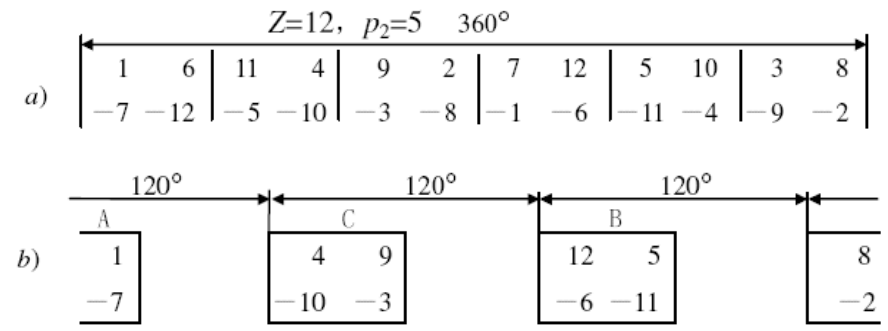

Figure 4. (a) Slot-number phase diagram $\left(Z=12, p_{2}=5\right)$, (b) Distribution of the slot numbers of 3 phases in Fig. 1(b) 
Comparing Fig. 3(b) with Fig. 4(b) reveals that the phase sequence for $p_{1}=7$ is in the order of $\mathrm{A}-\mathrm{B}-\mathrm{C}-\mathrm{A}$-, and the phase sequence for $p_{1}=5$ is in A-C-B-A-. In other words, the phase sequences for $p_{1}=7$ and $p_{2}=5$ are opposite; this satisfies the condition for BDFM operation.

Table 1 lists the harmonic analysis of the resultant MMF produced by the three phase currents when the coil span is chosen as 1 slot $(y=1)$. The chording factor for both $p_{1}=7$ and $p_{2}=5$ is equal to 0.9659 , resulting in a high winding factor of 0.9330. This implies that the rotor winding has high utilization rate, a unique feature for the proposed design method based on the slot MMF harmonics.

TABLE I. HARMONIC ANALYSIS OF THE RESULTANT ROTOR MMF

\begin{tabular}{|c|c|c|c|c|c|}
\hline \multirow{2}{*}{$\begin{array}{l}\text { Pole- } \\
\text { pair }\end{array}$} & \multirow{2}{*}{$\begin{array}{l}\text { Distribution } \\
\text { factor }\end{array}$} & \multirow{2}{*}{$\begin{array}{l}\text { Chording } \\
\text { factor }\end{array}$} & \multirow{2}{*}{$\begin{array}{l}\text { Winding } \\
\text { factor }\end{array}$} & \multicolumn{2}{|c|}{ Resultant MMF (\%) } \\
\hline & & & & $\mathrm{FV}^{+}$ & Fv- \\
\hline 1 & 0.2588 & 0.2588 & 0.0670 & 35.8984 & 0 \\
\hline 5 & 0.9659 & 0.9659 & 0.9330 & 0 & 100 \\
\hline 7 & 0.9659 & 0.9659 & 0.9330 & 71.4286 & 0 \\
\hline 11 & 0.2588 & 0.2588 & 0.0670 & 0 & 3.2635 \\
\hline 13 & 0.2588 & 0.2588 & 0.0670 & 2.7614 & 0 \\
\hline 17 & 0.9659 & 0.9659 & 0.9330 & 0 & 29.4118 \\
\hline 19 & 0.9659 & 0.9659 & 0.9330 & 26.3158 & 0 \\
\hline 23 & 0.2588 & 0.2588 & 0.0670 & 0 & 1.5608 \\
\hline 25 & 0.2588 & 0.2588 & 0.0670 & 1.4359 & 0 \\
\hline
\end{tabular}

From Table I, it can be seen that the harmonics with $Z+p_{2}=17$ and $Z+p_{1}=19$ pole-pairs have also high winding factor of 0.9330. Compared to the $p_{1}=7$ and $p_{2}=5$ pole-pair components, the 17 and 19 pole-pair harmonics have considerably higher number of pole-pairs and lower magnitude so their effect on the machine performance is not significant. As to the component of 1 pole-pair, although its magnitude seems high (35.8984\%), it does not affect greatly the machine performance. This is the common feature of low order components $(v<1)$.

The connection diagram of the 3 phase windings is illustrated in Fig. 5.

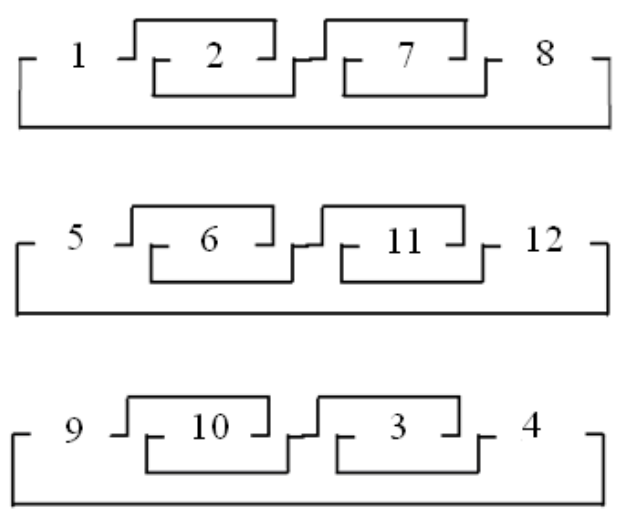

Figure 5. Winding connection of a wound rotor (12 slots, 7/5 pole-pairs)

The machine $\left(Z_{1}=12, y=1\right)$ has a uniform air gap but it acts as a salient rotor. Therefore, the coil manufacturing is very simple, which is an important factor for low speed high power machines. This is the advantage of the slot harmonics method in the aspect of rotor structure.
Although theoretically the selection of $p_{2}$ and $Z$ is quite arbitrary (only if the relation of $p_{1}=Z-p_{2}$ is satisfied), we normally choose $p_{2}<p_{1}$, in order to reduce the rating of the control winding.

\section{BDFM PROTOTYPE}

The designed rotor winding has been wound in an YZR112 induction machine. The stator has 36 slots, in which two 3phase windings of $p_{1}=7$ and $p_{2}=5$ pole-pairs are separately placed. The rotor has 24 poles and its winding connection diagram is shown in Fig. 6, where $y=2$.

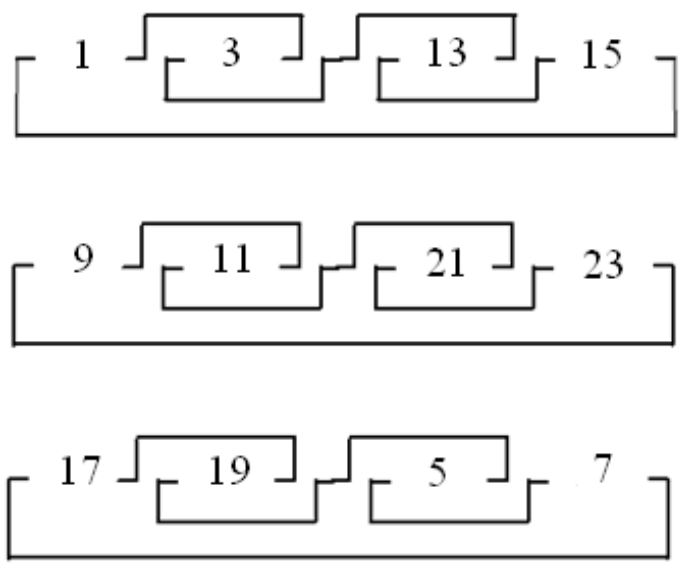

Figure 6. Winding connection of a wound rotor ( 24 slots, 7/5 pole-pairs, $\mathrm{y}=2)$

The prototype has been tested at no-load. The power winding $\left(p_{1}=7\right)$ is directly connected to the grid with a voltage of $150 \mathrm{~V}$. The control winding $\left(p_{2}=5\right)$ is connected via a varying voltage varying frequency power converter $(U / f=200 / 50)$. The experimental results are listed in Table 2, showing that the slot harmonic wound rotor BDFM can effectively adjust the machine speed by varying the frequency of electronic converter of the control winding.

TABLE II. NO-LOAD SPEED VARYING TEST

\begin{tabular}{|l|l|l|l|}
\hline $\begin{array}{l}\text { Converter } \\
\text { frequency (Hz) }\end{array}$ & $\begin{array}{l}\text { Rotor speed } \\
(\mathrm{r} / \mathrm{min})\end{array}$ & $\begin{array}{l}\text { Power winding } \\
\text { current (A) }\end{array}$ & $\begin{array}{l}\text { Control winding } \\
\text { current (A) }\end{array}$ \\
\hline 2 & 260 & 2.70 & 0.40 \\
\hline 4 & 270 & 2.70 & 0.50 \\
\hline 6 & 280 & 2.70 & 0.65 \\
\hline 8 & 290 & 2.65 & 0.85 \\
\hline 10 & 300 & 2.65 & 1.00 \\
\hline 12 & 310 & 2.65 & 1.15 \\
\hline 14 & 320 & 2.60 & 1.30 \\
\hline 16 & 330 & 2.60 & 1.45 \\
\hline 18 & 340 & 2.60 & 1.60 \\
\hline 20 & 350 & 2.55 & 1.73 \\
\hline 21 & 355 & 2.55 & 1.80 \\
\hline 23 & 365 & 2.55 & 1.88 \\
\hline 25 & 375 & 2.50 & 1.98 \\
\hline 27 & 385 & 2.50 & 2.10 \\
\hline 29 & 395 & 2.47 & 2.19 \\
\hline 31 & 405 & 2.45 & 2.27 \\
\hline 35 & 425 & 2.40 & 2.40 \\
\hline & & & \\
\hline
\end{tabular}




\section{CONCLUSION}

This paper presents a preliminary investigation on developing a brushless doubly fed machine based on the theory of slot harmonics of magnetomotive force, aiming to achieve high winding factor and power efficiency. Preliminary analysis and experiment show that the motor can vary speed smoothly as expected. Detailed theoretical analysis and experimental study are being carried out.

\section{REFERENCES}

[1] A. K. Wallace, R. Spee, and G. C. Alexander, "The brushless doubly-fed machine: its advantages, applications and design method," in Proc. $6^{\text {th }}$ Int. Conf. on Electrical Machines and Drives, Sep. 1993, pp. 511-517.

[2] X. Wang, P. C. Roberts, and R. A. McMahon, "Studies of inverter ratings of BDFM adjustable speed drive or generator system," in Proc. $6^{\text {th }}$ Conf. Power Electronics and Drives, Kuala Lumper, Malaysia, Dec. 2005.

[3] R. A. McMahon, P. C. Roberts, X. Wang, and P. J. Tavner, "Performance of BDFM as generator and motor," IEE Proc. - Electr. Power Appl., vol. 153, no. 2, pp. 289-299, Mar. 2006.

[4] P. Tanver, J. M. T. Chick, and E. Abdi-Jalebi, "A brushless doubly-fed machine for use in an integrated motor/converter, considering the rotor flux," in Proc. IEE Int. Conf. Power Electronics, Machines and Drives, Dublin, Ireland, April 2006.

[5] S. Williamson, A. C. Ferreira, and A. K. Wallace, "Generalised theory of the brushless doubly-fed machine. Part 1: analysis," IEE Proc. Electr. Power Appl., vol. 144, no. 2, pp. 111-122, Mar. 1997.

[6] A. R. W. Broadway and L. Burbridge, "Self-cascaded machine: a low speed motor or a high frequency brushless generator," Proceedings of Institution of Electrical Engineers, vol. 117, pp. 1277-1290, 1970.

[7] F. T. Chapman, "The production of noise and vibration by certain squirrel cage induction motor,” Journal of IEE, vol. 61, pp. 39-48, 1923. 